\title{
Experimental Thermal/Moisture Mapping of Industrial Safety Helmets
}

\author{
Z.W. Guan, A.R. Dullah, and H.L. Zhou \\ Department of Engineering, University of Liverpool, U.K \\ Zhongwei.Guan@liv.ac.uk
}

\begin{abstract}
This paper presents the research on thermal/moisture mapping of typical industrial safety helmets using match-head-sized sensors. Three types of the industrial safety helmet were tested, one without ventilation openings, one with small ventilation holes made by the researcher, and one with manufacturing ventilation openings in the top region. Up to eight subjects were tested for each type of helmets in various ambient conditions. Results give the original measurements of the in-helmet micro climate. Results also show some interested interaction between the in-helmet temperature and relative humidity.
\end{abstract}

Keywords: comfort, industrial helmet, micro climate, perception, thermal/ moisture mapping.

\section{Introduction}

Construction or assembling of a manufacturing line is usually a physically demanding activity with workers working for periods of up to 8 hours in a day. In general, such activity could be even more demanding by the fact that workers are required to wear protective equipment in order to prevent serious injury that may result from being hit by falling nuts and/or bolts. Combined with the fact that construction or assembling are often carried out in the heat of summer, this may give rise to physiological and psychological strains for workers who have to wear helmets to protect their heads from injury by law. It is therefore vital to minimise any discomfort that may result from this equipment, in order to ensure the optimal conditions are available for the user. This discomfort may be either: thermal discomfort - in terms of heat and sweat, or mechanical - as a result of friction or irritation.

Research on strength of helmets under impact loading has been carried out extensively [1-4], since protection offered to users must be the most important safety issue for helmets. Various designs and material selections were made to maximise impact resistance of the helmet. An overall review of research on industrial helmet design was given by Proctor in early 1980s [5]. The review covered statistics on the incidence and severity of head injuries in accidents where helmets were being worn, as compared with those where helmets were not being worn. It also covered biomechanical evidence and helmet testing. However, the comfort dealt by the review was for contact mechanical pressure, although the review pointed out discomfort 
could also be caused by a high temperature inside the helmet. Therefore, thermal comfort was not a major issue at that time for industrial helmets, although research on how skin temperature affect on sweating and aerobic performance during severe work was carried out [6].

Thermal comfort has drawn attention and attracted some research since 1970s. Early research was undertaken by using modular liquid-cooled helmet liner in astronaut helmets to improve thermal comfort [7]. However, the serious research was only initiated early 1990s. Abeysekera and Shahnavaz [8] carried out ergonomics evaluation of modified industrial helmets to be used in tropical environments. Liu et al [9] undertook subjective evaluation in warm field conditions based on human perception and the corresponding sweating manikin head. Redesign of an industrial helmet was also carried out to improve its thermal properties [10]. In this research thermal couples were used to produce the temperature contour underneath the helmet in a manikin system. Furthermore, design recommendations with ventilation paths were made. More recently, Davis et al [11] undertook investigations how ventilation affect safety helmets in a hot environment. Psychophysical results showed that ventilation contributes to greater helmet comfort. In general, although there were some research activities on thermal comfort of industrial helmets, such research was not extensive, also only related to subjective physiological and psychophysical responses and/or manikin measurements. The only direct measurements of multipoint temperatures and the relative humidity $(\mathrm{RH})$ were carried out inside a shoe for studying of the shoe climate [12 - 14].

In this paper, a test rig was developed to measure multi-point temperature and the RH inside an industrial helmet using micro sensors. Total thirteen locations were chosen to pick up measurements, which represent regions of the front, back, top, left and right of the helmet. There were three types of helmets tested, one without ventilation openings, one with small ventilation holes made by the researcher, and one with manufacturing ventilation openings in the top region. Up to eight subjects were tested for each type of helmets in various ambient conditions. Typical test duration was about 50 minutes, which was comprised of resting and walking periods on a treadmill. Experimental results show that the $\mathrm{RH}$ varies significantly inside a helmet whilst the corresponding temperatures change gradually depending upon ambient conditions. Typical variations of the temperature and the $\mathrm{RH}$ inside a helmet are $1 \sim 1.5{ }^{\circ} \mathrm{C}$ and $25 \sim 35 \%$ respectively for a relatively hot ambient temperature of about $30^{\circ} \mathrm{C}$, whilst $2 \sim 3^{\circ} \mathrm{C}$ and 10 20\% respectively for a comfortable ambient temperature of about $24^{\circ} \mathrm{C}$. These results show that even though the temperature inside a helmet does not vary greatly the corresponding RH can still change greatly. This gives scope to improve thermal comfort of a helmet since the RH is closely linked to it. Discussions on how to improve the thermal comfort are also given based on this pilot study.

\section{Experimental Work}

A test rig was developed to measure multi-point temperature and the relative humidity inside an industrial helmet using micro sensors. The test rig includes an industrial 

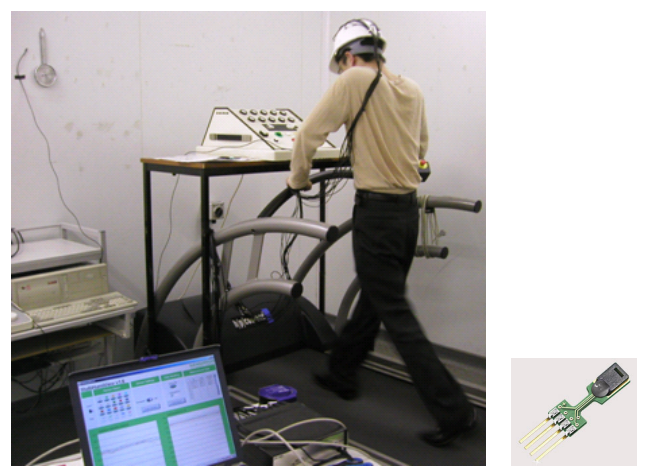

Fig. 1. The apparatus and subject during walking session

safety helmet with 13 sensors attached, a data logger, and a laptop. Two extra sensors were used to record the ambient conditions. Figure 1 shows an on-going test.

There were three types of commercially available industrial safety helmets tested. The Type I and Type II helmets were from the same white helmets except the Type II was provided with 22 small holes ( $3 \mathrm{~mm}$ in diameter) in the front, the side and the top areas. The Type III helmet was the red helmet that had 6 manufacturing ventilation openings sized 2 x $5 \mathrm{~mm}$ each on the top region. Figure 2 shows the industrial safety helmets used in the test.

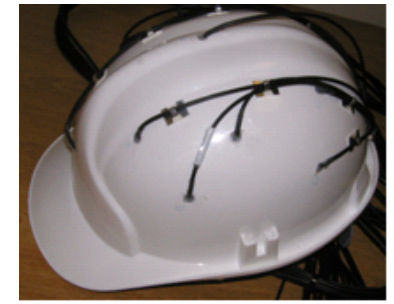

Type I helmet,

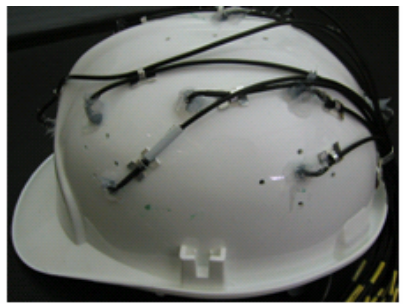

Type II helmet,

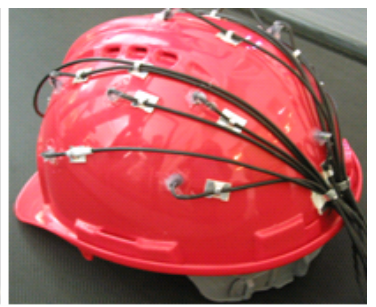

Type III helmet,

Fig. 2. Industrial safety helmets used in the study

The sensors used are capable of measuring the temperature and the relative humidity by using the same probe.

Total thirteen locations were chosen to pick up measurements, which represent regions of the front, the back, the top, the left and the right of a helmet. The selected positions were symmetrical, as shown in Figure 3. In order to embed the sensors, 13 holes with the diameter of $5 \mathrm{~mm}$ were drilled on the helmet. Sensors were placed above the inner surface of a helmet in a certain distance to avoid any direct contact to the head. In order to secure the position and maintain the original micro climatic conditions inside a helmet, all holes were sealed with silicone glue. 


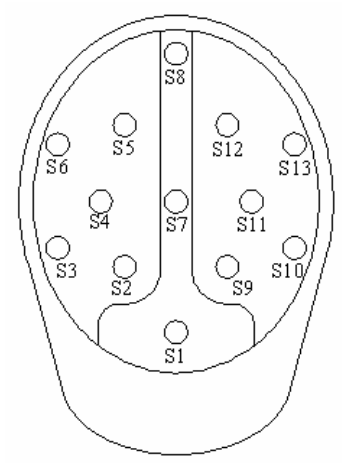

Fig. 3. The location of the sensors

The tests were carried out in the gymnasium at the Liverpool University Sport Centre. Up to eight healthy subjects were tested for each type of the helmets in various ambient conditions. All subjects were required to fill a consent form before carrying out the test. Typical test duration was about 50 minutes, which was comprised of resting and walking periods on a treadmill. Each resting and walking took about 10 minutes. The speed of tread mill was set at a walking speed of $5 \mathrm{~km} / \mathrm{h}$ and measurements of the temperature and the RH were recorded every 5 seconds. 15 data were collected each times i.e. 13 from inside the helmet and other 2 from the ambient.

To asses the perception of the subject during the test, the thermal and moisture subjective perception forms and questionnaires were designed. The subjects were asked to fill both perception forms in every 10 minutes starting from $t=0$ minutes. Both subjective perceptions are based on 5 scales. For temperature the scale are 1-cold, 2-cool, 3-neutral, 4-warm and 5-hot. The moisture scales are 1-wet, 2- slightly wet, 3-neutral, 4-slightly dry and 5-dry. The subjects were also asked to tick the area/areas where they felt hot, humid and uncomfortable for five areas, as shown in Table 1. All subjects were also asked to suggest the area/areas where should have openings.

Table 1. The breakdown of sensor areas

\begin{tabular}{l|l}
\hline Area & Sensor Locations \\
\hline Front & Sensor 1 \\
\hline Left & Sensor $2,3,4,5$ \& 6 \\
\hline Right & Sensor $9,10,11,12$ \&13 \\
\hline Top & Sensor 7 \\
\hline Back & Sensor 8 \\
\hline Ambient & Sensor $14 \& 15$ \\
\hline
\end{tabular}

\section{Result and Discussion}

In general, when the helmet was put on, the temperature and humidity inside the helmet increased straight away. As the subject started to walk, both temperature and the relative humidity are decreased due to the dynamic air flow between the ambient 
and the inside the helmet. Such air flow introduced efficient heat exchanges, which is good to the thermal comfort. The pattern continued until the end of the test.

Table 2 shows three typical ambient conditions and variations of the temperature and the relative humidity for the same position during the test for three types of the helmets. Clearly, for helmets with ventilation openings, more variations on both inhelmet temperatures and the RHs are indicated.

Table 2. The summary of the temperature and the relative humidity variations inside helmets during the tests

\begin{tabular}{ccccccc}
\hline \multirow{2}{*}{$\begin{array}{l}\text { Helmet } \\
\text { type }\end{array}$} & \multicolumn{3}{c}{ Temperature $\left({ }^{\circ} \mathrm{C}\right)$} & \multicolumn{3}{c}{ Relative Humidity (\% RH) } \\
\cline { 2 - 7 } & Ambient & $\begin{array}{l}\text { Variation } \\
\text { (Static) }\end{array}$ & $\begin{array}{l}\text { Variation } \\
\text { (Walking) }\end{array}$ & Ambient & $\begin{array}{l}\text { Variation } \\
\text { (Static) }\end{array}$ & $\begin{array}{l}\text { Variation } \\
\text { (Walking) }\end{array}$ \\
\hline I & 25 & $0.5-1.3$ & $0.5-0.7$ & 50 & $2-23$ & $2-10$ \\
\hline II & 22 & $0.5-1.4$ & $0.5-1.8$ & 55 & $5-20$ & $5-24$ \\
\hline III & 29 & $0.5-1.5$ & $0.5-1.2$ & 45 & $5-23$ & $5-28$ \\
\hline
\end{tabular}

In order assess the relative changes of the in-helmet temperature and the relative humidity against the ambient conditions after the measurement is stabilised, the corresponding parameters are defined as follows:

$$
\begin{aligned}
& \Delta T(\%)=\frac{T_{\max }-T_{\min }}{T_{\text {ambient }}} \\
& \Delta R H(\%)=\frac{R H_{\max }-R H_{\min }}{R H_{\text {ambient }}}
\end{aligned}
$$

\subsection{The Type I Helmet Without Ventilation Holes}

The most of the subjects showed the relatively high and low temperatures at top/left and front/back areas, respectively. In terms of the relative humidity, most of the subjects showed the relatively high and low humidity at the top/front and the back areas, respectively. Figure 4 gives the temperature and the $\mathrm{RH}$ versus the testing duration for a subject, respectively.
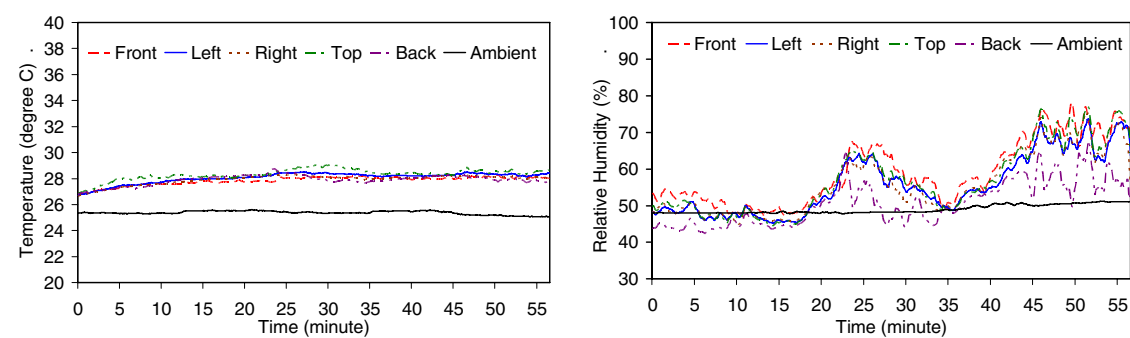

Fig. 4. In-helmet temperature and the RH versus test time for the Type I helmet 
The type I helmet does not have any ventilation openings. There is hardly any heat/moisture exchange through the top region of the helmet, except the bottom circumferential air gap. Therefore, temperature measurements inside the helmet pretty close to each other. However, it is worth pointing out that the $\mathrm{RH}$ is building up through the testing period, also the change of the $\mathrm{RH}$ from location to location is significant. The relative changes of the in-helmet temperature and the RH against the ambient condition $\Delta T(\%)$ and $\Delta R H(\%)$ are $5.8 \%$ and $67.6 \%$, respectively. The relatively high temperature measured on the top region is due to that the heat is moving up but there is no opening allowing it to escape. Also sweating on the top region is low which does not easy the temperature building up. On the contrary, the higher $\mathrm{RH}$ in the front caused by sweating may contribute the relatively low temperature measured, due to water vapour.

The subjective perceptions of the Helmet I show that the most hot and wet areas are front area, even though the temperature measurement does not support this. This may be blamed by the high RH. A humid local environment in the front could give the subject such feeling. Figure 5 shows the averaged thermal and moisture perceptions, respectively. These bar charts indicate that the hot thermal feeling coincides with the wet humidity feeling.

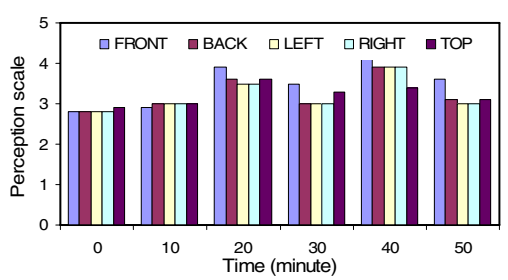

Thermal perception

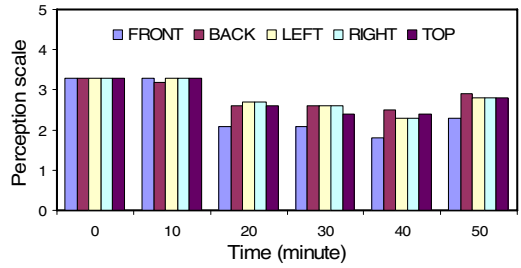

Relative humidity perception

Fig. 5. Averaged subject perceptions

\subsection{The Type II Helmet with Small Ventilation Holes}

In most of the cases, the left/right sides and the top areas show relatively high temperatures, whilst the front and the back relatively low temperature. However, the temperature in the back area tends to catch up, which gives the similar readings to that in the side in one or two occasions. The RHs demonstrate a general up trend for almost all cases. The RHs in the front and the back fluctuate the most, which are usually across over with each other through the walking and resting periods and also gives the upper and lower bound readings. Figure 6 shows typical measurements.

It can be seen that the RHs in the top and the back areas are decreased significantly during the walking period due to better air movement, also increased significantly during the resting period due to lack of air movement. In addition the chart indicates the coincidence between the temperature and the $\mathrm{RH}$ in some extent, i.e. the higher temperature corresponding to the higher $\mathrm{RH}$. The relative changes of the in-helmet temperature and the $\mathrm{RH}$ against the ambient condition $\Delta T(\%)$ and $\Delta R H(\%)$ are $9 \%$ and $42.2 \%$, respectively. The small ventilation holes seems having a certain effects on 

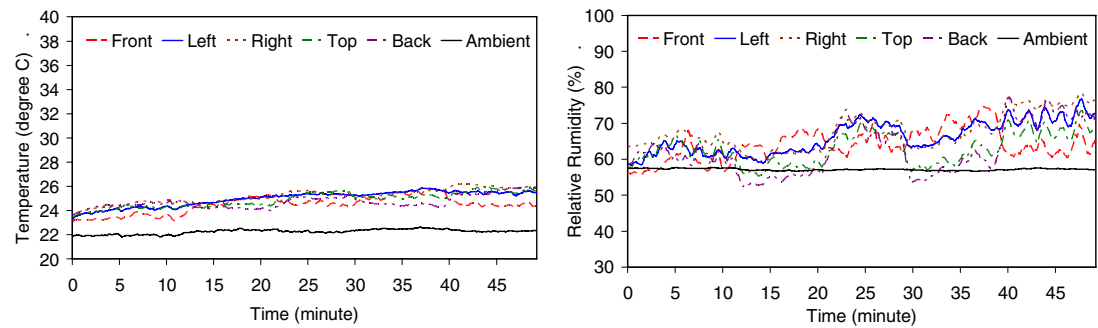

Fig. 6. In-Helmet Temperature and the RH Versus Test Time for the Type II Helmet

the in-helmet micro climate in terms of lower variation of the RH comparing with the Type I helmet. However, in the comfortable ambient conditions of $22^{\circ} \mathrm{C}$ and $57 \% \mathrm{RH}$, such effect is less significant.

Table 3 shows the summary of the questionnaire answer for the Type II helmet. The table shows that the majority of the subjects feel that the front area is the hottest, most humid, most uncomfortable and need openings. Such perception data can only be taken as a rough indication, especially for such small number of subjects.

Table 3. The summary of questionnaire answers for the Type II helmet

\begin{tabular}{lcccccc}
\hline & Front & Back & Left & Right & Top & No comment \\
\hline Hottest & 5 & 1 & 0 & 0 & 1 & 1 \\
\hline Most Humid & 6 & 1 & 0 & 0 & 0 & 1 \\
\hline Most Uncomfortable & 3 & 1 & 0 & 0 & 3 & 1 \\
\hline Opening suggestion & 3 & 3 & 0 & 0 & 0 & 2 \\
\hline
\end{tabular}

\subsection{The Type III Helmet with Manufacturing Ventilation Openings}

The relatively high temperature regions are shown in the side and the back areas, with the relatively low temperature in the front and the top areas. For the relative humidity, most of the subjects give the relatively high $\mathrm{RH}$ measurements in the side and the back areas and the relatively low RH in the front and the top regions. Figure 7 shows typical measurements. The in-helmet temperatures are gradually increasing in the first
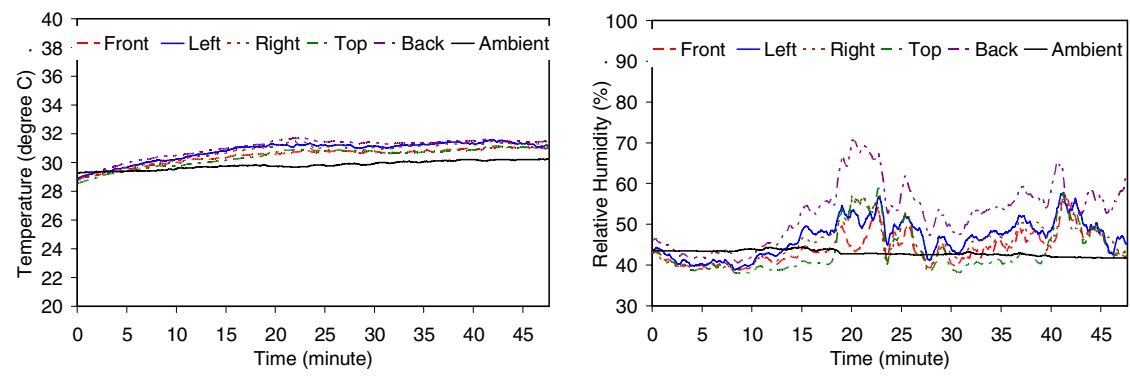

Fig. 7. In-helmet temperature and the RH versus test time for the type III helmet 
22 minutes, and then reach an almost stable condition afterwards. The highest difference from location to location is only about $1{ }^{\circ} \mathrm{C}$. However, the pattern of the $\mathrm{RH}$ is quite different from that for the Helmet Type I. The high $\mathrm{RH}$ in the back area may be caused by no ventilation openings there, which helps the RH builds up. The general trend of the $\mathrm{RH}$ is almost along the horizontal axis. The highest relative changes of the in-helmet temperature and the $\mathrm{RH}$ against the ambient condition $\Delta T(\%)$ and $\Delta R H(\%)$ are $3.4 \%$ and $75 \%$ at about the $22^{\text {nd }}$ minute, respectively. Such relative changes are gradually reduced. Big manufacturing openings on the top of the helmet do have some positive effects on the in-helmet micro climate. The highest RH recorded is about $70 \%$ for a high ambient temperature of $29{ }^{\circ} \mathrm{C}$, which is less than that (77.5\%) for the Helmet Type I.

Table 4 shows the summary of questionnaire answers. It is found that the majority of the subjects feel that front area is the hottest, most humid, most uncomfortable and needs openings. However, the perception is not quite coincided with the measurements. This may be partially caused by different ambient conditions.

Table 4. The summary of questionnaire answers for the Helmet Type III

\begin{tabular}{lcccccc}
\hline & Front & Back & Left & Right & Top & No comment \\
\hline Hottest & 6 & 1 & 0 & 0 & 0 & 1 \\
\hline Most Humid & 5 & 3 & 0 & 0 & 0 & 0 \\
\hline Most Uncomfortable & 5 & 0 & 3 & 0 & 0 & 0 \\
\hline Opening suggestion & 5 & 1 & 0 & 0 & 1 & 1 \\
\hline
\end{tabular}

The results of this study show that although the in-helmet temperatures from location to location do not vary much, their patterns are still noticeably different for these three types of helmets. The in-helmet temperature varies in a relatively small amount for the Type I helmet due to no ventilation hole, whilst in a higher amount of change for the Type II and III helmets with ventilation openings. It is likely that ventilation openings contribute more air movement in the corresponding regions inside the helmet, which cause the temperature with a higher spread. More interesting phenomenon lays on the relative humidity. For the Type I helmet, as there is limited air exchange higher RHs are usually recorded in the front, the side and the top as expected. Also the changes of the $\mathrm{RH}$ in the walking and rest periods are great. With introducing limited ventilation openings to the Type II and III helmets, there are some in-helmet RH shifts. The RH in the back is clearly increased a lot and becomes the relatively high $\mathrm{RH}$, and the $\mathrm{RH}$ on the top is decreased as certain amount of moisture can escape from the openings.

Although the test results show interesting phenomena, the measurements were carried out in uncontrolled ambient conditions. This gives difficult to compare results with each other. Future experimental work needs to be conducted in an environmental chamber with fully controlled climate conditions or in a less disturbed room with partial control of temperature and the relative humidity. 


\section{Conclusion}

A test rig has been developed to obtain thermal/moisture mapping of industrial safety helmets. The rig can pick up both temperature and the relative humidity in 13 locations inside a helmet. Three types of the helmet, with and without ventilation openings, have been tested. Measurements reveal that the ventilation openings are crucial to regulate the micro climate inside the helmet, so as to the thermal comfort. The initial output may be useful to helmet manufacturers to consider where to make ventilation openings. More research needs to be undertaken on precise thermal/moisture mapping and link it to a more broad perception base, furthermore to computer modelling. However, these preliminary results pave the way to undertake further research leading to optimise thermal comfort of the helmet.

\section{References}

1. Proctor, T., Rowland, F.J.: Development of standards for industrial safety helmets. Occupational Accidents 8, 181-191 (1986)

2. Rowland, F.J., Patel, B., Keithley, J.H.: Some industrial and climbing helmets subjected to a range of impact energies. Occupational Accidents 10, 29-37 (1988)

3. Gilchrist, A., Mills, N.J.: Construction site workers helmets. Occupational Accidents 9, 199-211 (1987)

4. Mills, N.J., Gilchrist, A.: Industrial helmet performance in impacts. Safety Science 16(34), 221-238 (1993)

5. Proctor, T.: A review of research relating to industrial helmet design. Occupational Accidents 3, 259-272 (1982)

6. Davies, C.T.M.: Influence of skin temperature on sweating and aerobic performance during severe work. Journal of Applied Physiology 47(4), 770-777 (1979)

7. Williams, B.A., Shitzer, A.: Modular liquid-cooled helmet liner for thermal comfort. Aerospace Medicine 45(9), 1030-1036 (1974)

8. Abeysekera, J.D.A., Shahnavaz, H.: Ergonomics evaluation of modified industrial helmets for use in tropical environments. Ergonomics 31(9), 1317-1329 (1988)

9. Liu, X., Abeysekera, J., Shahnavaz, H.: Subjective evaluation of three helmets in cold laboratory and warm field environment. Industrial Ergonomics 23(1), 223-230 (1999)

10. Hsu, Y.L., Tai, C.Y., Chen, T.C.: Improving thermal properties of industrial safety helmets. Industrial Ergonomics 26(2), 109-117 (2000)

11. Davis, G.A., Edmisten, E.D., Thomas, R.E., Rummer, R.B., Pascoe, D.D.: Effects of ventilated safety helmets in a hot environment. Industrial Ergonomics 27(5), 321-329 (2001)

12. Covill D.G, Guan Z.W. , Pope D.J., Bailey M.: The effect of shoe fit on subjective responses, temperature and relative humidity levels. In: Proceedings of 4th International Conference on The Engineering of Sport, Kyoto, Japan, pp. 588-594 (September 3- 6, 2002)

13. Covill, D.G: Experimental and numerical modelling of shoe climate, PhD Thesis, University of Brighton (2005)

14. Raval, H., Guan, Z.W., Bailey, M., Covill, D.G.: Simplified 3-D FE model of thermal conditions inside a shoe. In: 9th International Conference on Advanced Computational Methods and Experimental Measurements in Heat and Mass Transfer, July 5-7, 2006. The New Forest, UK (2006) 